\title{
CAPACIDADE FUNCIONAL E QUALIDADE DE VIDA DE IDOSOS
}

\author{
Rita de Cassia Lanes Ribeiro ${ }^{1}$ \\ Alice Inês Oliveira e Silva ${ }^{2}$ \\ Celina Maria Modena ${ }^{3}$ \\ Maria do Carmo Fonseca ${ }^{4}$
}

\section{Resumo}

Uma metodologia qualitativa, observação participante, foi utilizada para analisar as representações de envelhecimento e qualidade de vida, tal como percebidos pelos idosos. Trabalhou-se com vinte e nove idosos membros do Grupo da Terceira Idade na cidade de Viçosa Minas Gerais. Por meio de entrevista semi-estruturada, gravada e transcrita, coletou-se dados sobre seus modos de vida, estilos de vida, o que é ser idoso e seus papéis sociais, saúde, qualidade de vida e os fatores que afetam a sua autonomia. Evidenciou-se que as representações de envelhecimento e qualidade de vida ultrapassam os limites biomédicos e se revestem de significados próprios. Para os idosos qualidade de vida significa a capacidade de realizar atividades sem interferência de outras pessoas. Eles também consideram velhas as pessoas que são incapazes de desempenhar qualquer atividade física e/ou mental.

Palavras-chave: Envelhecimento; Qualidade de vida; Representação do Envelhecimento.

\footnotetext{
${ }^{1}$ Enfermeira, Departamento de Nutrição e Saúde, Universidade Federal de Viçosa, Viçosa MG. Doutora em Epidemiologia. E-mail:rribeiro@ufv.br

${ }^{2}$ Bacharela em Jornalismo, Departamento de Economia, Universidade Federal de Viçosa, Viçosa MG. Doutora em Antropologia.

${ }^{3}$ Médica Veterinária e Psicóloga, Departamento de Medicina Preventiva, Universidade Federal de Minas Gerais, Viçosa MG. Doutora em Epidemiologia.

${ }^{4}$ Bacharel em Ciências Econômicas, Faculdade de Ciências Econômicas, Universidade Federal de Minas Gerais, CEDEPLAR (Centro de Desenvolvimento e Planejamento Regional), Viçosa MG. Doutora em Demografia.
} 


\begin{abstract}
Participant observation, a qualitative methodology, was used to analyze the representation of aging and the quality fo life, as so perceived by elderlies. Data from twenty-nine members of the "Third Age" group of Viçosa, Minas Gerais, in Brazil, was collected. Semi-structured interviews were recorded and then transcripted. From those inteviews data about ways of living, lifestyle, the definition of the word "elderly", their social roles, health, the quality of life, how those factors affected elderly lives, were collected. Results of this study showed that the representations of aging and qulaity of life overcome biomedical limits and are overlayed with their own meanings Quality of life for an elderly person means being able to perform activities without the interference of others. They consider an old person someone who cannot perform any physical and/or mental activity.
\end{abstract}

Keywords: Aging; Quality of Life; Representation of Aging.

\title{
1 Introdução
}

A qualidade de vida da população idosa está associada à manutenção da capacidade funcional ou da autonomia. Segundo Rowe; Kahn (1987), autonomia é a medida pela qual os indivíduos são capazes de tomar decisões em relação a escolha de atividades, métodos, maneiras de participação social, tempo de duração de atividades, dentre outras. Os limites colocados para o idoso pela família e sociedade configuram uma perda de autonomia que lhes apontam não ter os mesmos direitos que lhes cabiam na vida adulta. Isto implica cobranças e exigências do adulto para com os idosos que os limitam, principalmente em relação às possibilidades de satisfação (FRANÇA, 1989).

Há que considerar que a qualidade de vida do indivíduo idoso está relacionada também à segurança sócio-econômica, ao bem-estar psicossocial à sensação de saúde, sendo que a saúde, está relacionada por sua vida passada, pela estrutura genética e pelo meio ambiente (DARNTON-HILL, 1995). Todos esses fatores são interrelacionados e sua importância relativa difere de uma sociedade para outra e de pessoa para pessoa. 
Segundo Andrade (1996), a qualidade de vida da população idosa pode estar associada também à impressão subjetiva de seu estado de saúde, e a influência dessa opinião é maior do que a saúde constatada. A compreensão do processo saúde/doença sob a ótica subjetiva da população em estudo através de uma abordagem qualitativa, levando-se em conta, valores, crenças e atitudes da população, levará à melhor compreensão dos fatores que afetam a autonomia e a qualidade de vida da população idosa, tal como eles são percebidos.

Alguns trabalhos sobre a autonomia, sobre os riscos de incapacidades, atividades de vida diária, para verificação da qualidade de vida, têm sido desenvolvidos, por meio de questionários padronizados, onde, têm sido apontadas as doenças crônicas e os eventos agudos (fraturas, acidentes vasculares cerebrais, artrites, entre outros) como as causas ou as geradoras de incapacidade, sendo realçada a importância do suporte social como mediador entre o status funcional e a qualidade de vida em idosos.

Críticas têm sido feitas sobre as avaliações de saúde em idosos que se limitam a uma avaliação de seu estado físico e mental e as conseqüências destes, no desempenho de atividades de vida diária. As avaliações devem, também, levar em consideração as condições econômicas e sociais e a situação ambiental como um todo.

Faz-se necessário não só uma avaliação multidimensional que forneça uma visão global da situação social e de saúde da pessoa, mas é preciso levar em consideração a questão das representações que cada indivíduo tem dos fatores que lhes são pertinentes, ou seja, o que é ser idoso e seus papéis sociais; representação de autonomia e fatores que a afetam; representações de saúde; qualidade de vida, entre outras coisas. A maioria de estudos têm sido elaborados onde pouca ou nenhuma visibilidade é dada aos significados simbólicos sobre o envelhecimento e seus desencadeamentos, vivenciados pelo sujeito que a vivencia.

Neste sentido o presente estudo tem como objetivo analisar a representação de envelhecimento e a qualidade de vida de idosos, tal como por eles percebidos. 


\section{Metodologia}

A característica metodológica deste estudo consiste de pesquisa qualitativa por meio do estudo de caso, que é uma técnica que permite analisar em profundidade por um período de tempo, um indivíduo, uma família, um grupo e um evento.

Realizou-se observação participante, após obtenção do consentimento informal do grupo e coletou-se dados sobre seus modos de vida, estilos de vida, o que é ser idoso e seus papéis sociais, saúde, qualidade de vida e os fatores que afetam a sua autonomia, por meio de entrevista semi-estruturada, gravada e transcrita. Os instrumentais metodológicos são os recomendado por Trivinos (1987), Minayo (1993), Haguete (1995).

\section{Caracterização dos Idosos Entrevistados e do Local da Pesquisa}

A pesquisa foi realizada com idosos participantes de um Grupo da Terceira Idade no Município de Viçosa, Minas Gerais, no período de novembro de 1997 a setembro de 1998.

A formação do Grupo da Terceira Idade se deu a partir da inserção das pessoas de mais idade que se cadastravam no Programa da Secretaria de Ação Social da Prefeitura Municipal. Para iniciar o programa a prefeitura o tornou público convidando as pessoas a participar e após algum tempo o conhecimento das pessoas sobre o grupo se deu por informações obtidas dos próprios participantes.

A maioria das pessoas do grupo mulheres, viúvas e poucas solteiras e casadas, há uma minoria de homens. Poucos freqüentaram a escola formal. Dos entrevistados, três são do sexo masculino sendo que um deles é viúvo e dois casados.

Algumas atividades como ginástica e aula de dança, ensaios do coral são desenvolvidos num clube no centro da cidade, o que facilita a participação dos seus freqüentadores, pois muitos deles moram no centro e outros vêm de bairros mais distantes (bairros de classe média, mas também de bairros populares). Alguns chegam a pé, outros de ônibus urbanos. 
Os idosos em estudo moram em bairro de classe média e média baixa, o aspecto econômico é estável levando em consideração os aspectos simbólicos das relações que a classe faz de sua posição e situação relativa (BOURDIEU ${ }^{5}, 1974$ apud LINS DE BARROS). A fonte de renda provém das suas aposentadorias que em sua grande parte foi por idade e/ou de pensões de seus cônjuges, pois raramente as mulheres do grupo trabalharam no serviço formal.

Observa-se que o padrão sócio-econômico da maioria, pode ser considerado como nível baixo, caracterizado por uma renda que não ultrapassa a 1,0 salário mínimo por pessoa, nível de instrução com apenas os primeiros anos de escolaridade, através do ensino informal (ensino em zonas rurais onde quem podia contratava um professor para ensinar as primeiras letras ao filho) com exceção de um caso com $1^{\circ} \mathrm{Grau}$ completo.

\section{Universo Estudado}

O número exato de pessoas a fazer parte do estudo não foi definido a priori, esse número foi se ampliando a medida que o estudo de campo era desenvolvido. Foram entrevistados vinte e nove pessoas, porém devido à recorrência de relatos foram utilizadas na análise dezessete entrevistas.

Das pessoas entrevistadas, vinte e seis são do sexo feminino e três idosos do sexo masculino, o que representa $89,65 \%$ e $10,34 \%$ respectivamente. $\mathrm{O}$ "Grupo da terceira idade" é freqüentado principalmente por mulheres com idades que variam de 55 a 87 anos de idade. Dos idosos estudados $48,27 \%$ são viúvos $37,93 \%$ casados e $13,79 \%$ solteiros.

As pessoas incluídas no estudo foram aquelas que mais chamavam atenção no grupo, devido sua comunicabilidade, ou por serem muito idosas e animadas, dentre outros predicados, que se observava nas anotações de campo. O local, data e horário para a entrevista foram marcado de acordo com a disponibilidade das pessoas envolvidas.

\footnotetext{
${ }^{5}$ BOURDIEU, Pierre. Condição de Classe e Posição de Classe. In: AGUIAR, Neuma (Org.). Hierarquias de Classes. Rio de Janeiro: Zahar, 1974. Apud LINS DE BARROS, 1998, p. 122.
} 


\section{Resultados e Discussão - Estilo de vida, condições de saúde e autonomia na velhice}

Em suas falas os idosos apontaram o que consideram importante para as pessoas de suas idades:

"Eu acho que as pessoas deve de passear, deve de andar, deve de conviver com as pessoas, com outras pessoas novas, a pessoa precisa se divertir, de descansar um pouco, fazer caminhada, sair pra respirar um pouco né? A pessoa que só fica dentro de casa, só pensa bobagem, a pessoa que fica dentro de casa fica triste, fica magoada, vê coisas que não gosta. Enquanto tá passeando, tá no meio dos amigos, tá divertindo, esquece o passado né?" (C. 63 anos, casada).

"O que é importante, importante é fazer o que podemos. A pessoa ter liberdade, não ter que [...] não pode fazer isso, não pode fazer aquilo, não pode fazer aquilo outro né, tem famíli: ô mamãe não pode fazer isso que a senhora é velha, o importante é a pessoa ser feliz, fazer o que quer fazer [...]" (M. A. 67 anos, casada).

As pessoas idosas podem permanecer ativas e independentes por muito tempo, desde que lhes sejam proporcionados apoio adequado. Essa capacidade de se manter independente funcionalmente, isto é a capacidade de realizar atividades sem a interferência ou influência de outras pessoas é uma das questões mais significativas da velhice (VERAS, 1994).

Os programas ora oferecidos aos idosos proporcionam uma melhoria em sua auto-estima na medida em que são livres para desenvolver atividades que julgam de qualidade. Em muitos relatos constatou-se que as atividades do grupo são um "compromisso" bem vindo que eles tem e um motivo para sair de sua rotina diária.

"Olha eu acho que [...], depois que a gente é [...] há muitas pessoas [...] a gente entra na terceira idade (se referindo ao grupo) a gente passa a entender os jovens melhor [...] E a gente começa a sentir que a gente também, é jovem, às vezes eu até começo achar que [...] é que a gente deixa de pensar em doença, a gente só sente dor quando é dor mesmo, mas a gente não fica inventando a dor. E um velho que só fica em casa ele só fica pensando em doença, ah eu fiz isso fiz aquilo fica com aquela mania boba e isso desaparece tudo [... ]" (R. 60 anos, casada). 
Nesse sentido a população idosa tem a expectativa de desfrutar, ainda por vários anos de uma vida saudável e ativa, com uma boa qualidade de vida. Qualidade de vida no idoso se relaciona, como citado anteriormente, com a "capacidade do idoso em desenvolver suas atividades de vida diária". Nas falas dos idosos eles percebem como satisfatória sua qualidade de vida mencionando como determinantes os seguintes fatores: bens de consumo, ter saúde, boa alimentação, carinho de familiares. A qualidade de vida da população idosa está relacionada com suas atividades cotidianas e da manutenção ou ganho de autonomia no seu meio familiar (DARNTON-HILL, 1995).

Considera-se também de grande importância as atividades que são desenvolvidas em contato com outras pessoas da mesma faixa etária: a convivência, os exercícios físicos moderados são atividades que proporcionam melhora na auto-estima do idoso, consequentemente sua qualidade de vida.

"Mas, eu desde que entrei acho uma maravilha, aqui a gente encontra colegas, eles tem muito carinho comigo, vou chegando eles abraçam [... . ficam perto, é muito bom não? A convivência [...]" (E. 87 anos, viúva).

Com esses exemplos confirma-se a fala de Veras, (1994) que diz que mais importante do que pesquisar doenças em populações idosas é constatar se estas os impedem a desempenhar suas atividades de vida diária.

Eles entretanto em muitas falas não deixaram de mencionar como "boa qualidade de vida" a pessoa que tem o que comer, ou onde morar ou o que tem emprego, boa alimentação, eles expressaram esses conceitos, como cidadãos comuns que estão inseridos no contexto social de crises em que vivem.

“[. . . ] importante pra gente ter saúde é uma boa alimentação, uma boa higiene, uma boa alimentação né, muito importante porque acha que alimentar bem é comer muito, muita carne, muito isso, muito aquilo, e [...] é saber alimentar [...]" (M.A. 67 anos, casada).

"Ah eu acho que é alimentar bem, ter uma alimentação balanceada, fazer assim [...] igual a gente faz, de sair, encontrar com as pessoas, fazer muita amizade.” (M. S. 67 anos, viúva). 
"Ah eu acho que uma boa alimentação tem utilidade né, a pessoa fazer tudo o que gosta, não ser obrigada né, a fazer aquilo que não gosta né, e isso tudo é bão pra saúde, é ter uma vida controlada." (R. 60 anos, casada).

Nas falas dos idosos quando indagado sobre o que consideram importante para ter saúde fizeram as seguintes colocações:

"[. . .] acho que pra ter saúde é a gente saber levar a vida, não abusar, eu pelo menos abusava, abusei. Fiz tudo enquanto errado na vida de novo, mas acho que quando a pessoa tem um trabalho de acordo, tem hora pra dormir certa, ele alimenta de acordo, ele não bebe demais, não abusa de nada, ele tem saúde e continua ter saúde e mais ter uma boa vida, a gente não tem condição pras coisa [. . .]" (Sr. J. 87 anos, viúvo).

"Eu sei, eu acho assim que toda vida eu tive saúde, mas sou fazedora de regime, se eu chegar no médico e ele falar assim, assim, eu não como não. Eu me domino [. . . ]" (E. 65 anos, solteira).

Portanto, percebeu-se que qualidade de vida para eles, na velhice, está muito relacionada com saúde e autonomia, com a possibilidade de exercerem as atividades de vida diária sem impedimentos.

Nas falas dos idosos havia uma forte associação entre velhice e falta de autonomia e consequentemente falta de saúde, ou seja consideravam como velhos e incapazes as pessoas impedidas de desempenhar suas atividades físicas e mentais. Os idosos percebem a velhice não ligada à idade cronológica mas enveredam essa discussão (ser idoso) para a questão da saúde, associando a velhice com a perda de saúde (CALDAS, 1997).

Seja qual for o tipo de insanidade, ela tem o poder de retirar o indivíduo de seu convívio social e para as pessoas que procuram atividades extra domésticas como é o caso do grupo, a doença, diga-se a incapacitante aparece como ameaça interrompendo o caminho que traçaram.

D. M. C. 68 anos, doméstica, relatou que ...

"[. . .] se a pessoa tem vontade de sair, passear, trabalhar, tem disposição, nunca é velho. Velho é quando cai numa cama e não levanta mais, esse é considerado velho." 
A qualidade de vida deve ser entendida como sendo a condição de existência dos homens/mulheres referidas ao modo de viver em sociedade, dentro dos limites colocados em cada momento para se viver o cotidiano. Significa também uma existência que satisfaça as exigências deste cotidiano, onde "viver impedido" acarretará sofrimento que se quer evitar através das ações de saúde. A realização da qualidade de vida no plano individual depende dessa conquista no plano coletivo, pois as possibilidades de cada cidadão encontram respostas ou limitações no plano coletivo da sociedade.

Uma reflexão também que se esboça é o conceito amplo e positivo de saúde e a necessidade de construção de uma prática que contribua para as mudanças nas condições de vida e saúde da população. A condução desta reflexão no presente trabalho se dá a partir da indagação do que seja qualidade de vida no particular contexto do grupo de idosos em estudo, levando-se em consideração também as necessidades variadas que se colocam no plano individual. Os idosos quando indagados sobre o que consideram como qualidade de vida, responderam:

"Ah, precisa de paz né, ter paz, não ter ninguém que amola, que fica fazendo a gente ficar com raiva e essas coisas assim que eu quando fico com raiva fico toda descontrolada mas, também aquilo passa logo [. . . É é paz, eu acho que é paz, pra mim é paz eu quando tô em paz pra mim tá tudo bom, não tem nada [. . .]" (J. 80 anos, viúva).

"Uma boa qualidade de vida é a gente [. . .] a gente ter família que a gente tem, isso é muito importante. Isso eu acho uma boa qualidade de vida, um dinheirinho a mais, né eu me conformo com que eu tenho. É pouco, mas me conformo com o meu [. . .]" (M.A. 67 anos, casada).

"[. . . ] eu acho que a gente tendo um dinheiro suficiente, pra gente manter, sem dever e sem ficar comprando assim[. . .] e ficar devendo, pagando juros. Isso tudo eu acho que é importante pra ter qualidade de vida [. . .]" (M. S. 67 anos, viúva).

$\mathrm{O}$ estudo de representações ou percepções sobre os fatores que afetam a autonomia, é de importância a medida que através deles, será possível entender suas implicações na vida do idoso e possibilitar o 
empreendimento de medidas preventivas para a melhoria da qualidade de vida da população idosa.

A identificação de problemas de saúde no idoso tem um grau de importância distinto do que ocorre nos demais grupos etários. Mais importante do que constatar uma determinada patologia é identificar se esse problema está impedindo o desempenho de atividades pelo idoso. As atividades de vida diária se mostram como um indicador sensível na definição da qualidade de vida do idoso.

"Sozinha e se preciso de ir ao médico, vou sozinha, ninguém fica sabendo, sabe assim às vezes mexe nas minhas coisas lá, aí vê e pergunta: ô mãe cê foi ao médico? Mas nem pra ir ao médico não gosto que fiquem sabendo [. . . ]" (D. M. A. 67 anos, casada).

"[. . . ] faço de tudo, não tenho ajuda de nada. Não tem quem lava um copo pra mim [...]" (C. 63 anos, casada).

"[. . . ] tudo eu faço sozinha, eu que tomo conta dos meus negócios, tudo sozinha, eu faço, vou a banco e tudo [. . . E Eu tenho uma companhia que vai comigo caminhar, minha prima, que ela também é viúva, mas pra minha casa vou sozinha, venho à missa sozinha [...]” (E. 65 anos, viúva).

"Ando tudo sozinho, vou daqui lá pra roça, vou pro Pau de Paina, vô lá no Paraíso a pé [. . . ] vou e volto [... .]" (T.J. 67 anos, viúva).

Do ponto de vista social, Beauvoir (1990) afirma que o estatuto da velhice é imposto ao homem pela sociedade à qual pertence. Portanto, não se pode considerar em separado os dados orgânicos e os fatos psicológicos eles se impõem mutuamente. A sociedade destina ao velho o seu papel, e o indivíduo é condicionado pela atitude prática e ideológica da sociedade em relação a ele.

\section{Conclusão}

A representação de qualidade de vida apresentada pelos idosos pesquisados, se relaciona com o estilo de vida, está ligada à autonomia, ao desempenho das atividades de vida diária, à segurança sócio-econômica, à compreensão dos fenômenos saúde-doença sob suas óticas subjetivas e às relações familiares. 
Os resultados deste estudo confirmaram, na cidade de Viçosa, Minas Gerais os aspectos considerados na literatura sobre a qualidade de vida do idoso e seus determinantes. As falas e as práticas observadas, assim como o uso do referencial teórico e da metodologia qualitativa deram o tom e a singularidade aos resultados. O tema foi ao longo do estudo sendo organizado pelos próprios sujeitos.

A classificação de velho para as pessoas que freqüentam o grupo, são baseadas não na aparência física, na idade cronológica, mas sim na falta de autonomia e falta de saúde, ou seja consideram que as pessoas são velhas somente a partir do momento em que estão doentes incapazes de desempenhar qualquer atividade física ou mental.

O estudo permitiu melhor compreensão desse curso da vida, havendo de servir como alerta aos profissionais de saúde, para elaboração de práticas preventivas a serem implementadas, visando a melhor qualidade de vida para essa população.

\section{Referências}

1 ANDRADE, C. J. M. Representações de Saúdeldoença e Alternativas Terapêuticas em Bairros da Periferia de Belo Horizonte (1994-1996). Belo Horizonte: UFMG, Escola de Veterinária, 1996. 113p. Dissertação (Mestrado em Medicina Veterinária Preventiva). Universidade Federal de Minas Gerais. 1996. 2 BEAVOIR, S. A Velhice. São Paulo: Difusão Européia de Livro, 1990.

3 CALDAS, C. P. Memória, Trabalho e Velhice: um estudo das memórias de velhos trabalhadores. In: VERAS, R. P. (Org.). Terceira idade: desafios para o terceiro milênio. Rio de Janeiro: Relume Dumará, 1997. p. 121-142.

4 DARNTON-HILL, L. El envejecimiento com salud y la calidad de la vida. In: FORO MUNDIAL DE LA SALUD, Geneva, 1995, v. 16, p. 381-391.

5 FRANÇA, L. H. P. Perspectivas Existenciais num Grupo de Idosos. Intercâmbio, Rio de Janeiro, v. 4, n. 2, p. 49-56, 1989.

6 FRANÇA, H. L.; SOARES, N. E. A Importância das Relações Intergeracionais na Quebra do Preconceito sobre a Velhice. In: VERAS, R. P. (Org.). Terceira Idade, Desafios para o $3^{\circ}$ Milênio. Rio de Janeiro: Relume Dumará, 1997. p. 143-169.

7 HAGUETE, T. M. F. Metodologias Qualitativas na Sociologia. $3^{\text {a }}$ ed. Petrópolis: Vozes, 1995. 224p. 
8 LINS DE BARROS, M. M. Velhice ou Terceira Idade? estudos antropológicos sobre identidade, memória e política. Rio de janeiro: F.G.V., 1998. 235p. 9 MINAYO, M. C. O Desafio do Conhecimento: pesquisa qualitativa em saúde. $2^{\mathrm{a}}$ ed. São Paulo: HUCITEC/ABRASCO, 1993. 262p.

10 ROWE, J. W.; KAHN, R. L. Human Aging: usual and successful. Science, Washington, DC, v. 237, p. 143-149, 1987.

11 TRIVIÑOS, A. N. S. Introdução à Pesquisa em Ciências Sociais: a pesquisa qualitativa em educação. São Paulo: Àtica, 1987. 165p.

12 VERAS, R. P. País Jovem com Cabelos Brancos - a saúde do idoso no Brasil. Rio de Janeiro: Relume Dumará, 1994. 224p. 